\title{
Carlos Pastore y el Instituto Histórico y Geográfico del Uruguay: redes intelectuales y homenajes en el Centenario de Artigas
}

Matías Borba Eguren*

\section{Resumen}

El presente trabajo analiza la participación de Carlos Pastore - intelectual y político paraguayo, exiliado en Montevideo en 1942 - en los homenajes a Artigas, realizados por el Instituto Histórico y Geográfico del Uruguay en 1950. Se busca establecer su papel como articulador entre el Instituto y otros paraguayos - en su mayoría exiliados -, aplicando técnicas del social network analysis y de text mining, para graficar la red político-historiográfica a su alrededor. Se pretende señalar cómo los homenajes a Artigas fueron una oportunidad para los exiliados paraguayos de utilizar el pasado como herramienta de militancia contra la situación política de Paraguay.

Palabras clave: Carlos Pastore - Instituto Histórico y Geográfico del Uruguay Artigas y Paraguay.

\section{Summary}

This paper analyzes the participation of Carlos Pastore - paraguayan intellectual and politician, exiled in Montevideo in 1942 - in the tributes to Artigas, made by the Instituto Histórico y Geográfico del Uruguay in 1950. Aims to establish its role as an articulator between the Institute and other Paraguayans - mostly exiles -, applying techniques of social network analysis and text mining, to plot the politicalhistoriographic network around them. It is intended to point out how the tributes to Artigas were an opportunity for Paraguayan exiles to use the past as a tool of militancy against the political situation in Paraguay.

Keywords: Carlos Pastore - Instituto Histórico y Geográfico del Uruguay - Artigas and Paraguay.

\footnotetext{
* Universidad de la República. E mail: matungo05@hotmail.com
} 


\section{Introducción ${ }^{1}$}

En 1950 el Uruguay conmemoró el Centenario de la muerte de José Gervasio Artigas, realizándose diversas actividades en su honor. Como señala Clarel de los Santos ${ }^{2}$, el centenario artiguista significó uno de los puntos más altos en la heroificación de su figura. En palabras del autor: «Las conmemoraciones de 1950 marcaron la percepción que tenian los uruguayos de su "Héroe Fundador" e incidieron en su culto y en la conformación de su imagen y memoria $\rangle^{3}$. La participación de distintas instituciones contribuyó en este auge de "mitificación" de Artigas, en un contexto de bienestar político, económico y social para el país.

Entre estas se encontraba el Instituto Histórico y Geográfico del Uruguay (en adelante, IHGU), presidido por Ariosto González para ese entonces. Como parte de los homenajes, el IHGU dictó un ciclo de conferencias en honor a Artigas. En 1952, el Instituto publica la recopilación de las intervenciones que se realizaron en este marco, bajo el título Artigas. Homenaje en el centenario de su muerte. Entre los participantes, y posterior publicación, se destacó la presencia de intelectuales paraguayos, entre ellos, Carlos Pastore.

Pastore se encontraba en Montevideo desde 1942, tras haber emprendido su exilio con el ascenso de Higinio Morínigo al frente del gobierno paraguayo (1940-1948). Abogado, historiador y militante del Partido Liberal, ocupó entre 1939 y 1940 el Departamento de Tierras en su país. Allí se encargó de estudiar los problemas de la propiedad de la tierra, y planteó una reforma agraria para solucionarlos. La muerte de José Félix Estigarribia, y el golpe de estado posterior, hicieron que Pastore dejara su puesto y terminara radicándose en Montevideo por más de treinta años.

1 Este trabajo se encuentra enmarcado en las actividades de mi tesis de posgrado de la Maestría en Humanidades - Opción Historia Rioplatense, de la Facultad de Humanidades y Ciencias de la Educación - UdelaR -. A su vez, forma parte de los primeros resultados de mi proyecto de iniciación a la investigación financiado por CSIC, titulado «Carlos Pastore: resistencia, exilio y escritura de la Historia en el Paraguay autoritario». Finalmente, este trabajo también se inscribe en las actividades llevadas a cabo en el Grupo Autoidentificado No 881537, “Tendencia y debates historiográficos en Uruguay y la región (siglos XIX y XX)", adscripto al Departamento de Historiología de la FHCE-UdelaR y coordinado por el Dr. Tomás Sansón Corbo.

2 De los Santos, 2012.

3 Ibid.: p. 25. 
En la capital uruguaya continúo su militancia en el Partido Liberal, enfrentándose a los distintos gobiernos autoritarios de su país. Además de ejercer su profesión, trabajó como periodista, e incursionó en la radio con su programa La hora de la liberación paraguaya, transmitido por Radio Ariel y El Espectador. La recopilación de sus audiciones fue publicada en su obra El Paraguay y la tiranía de Morinigo en 1947.

Su actividad intelectual le permitió establecer distintos vínculos con figuras importantes de la cultura y la política uruguaya, como por ejemplo Luis Batlle Berres, Arturo Ardao, Ariosto González, Luis Alberto de Herrera, Emilio Frugoni, entre otros. En 1952 es iniciado en la Gran Logia de la Masonería del Uruguay, donde en 1956 funda la Log:: Río de la Plata $\mathrm{N}^{\circ}$ 121, la cual se distinguió por recibir a emigrados de todas las regiones de América ${ }^{4}$. En relación a sus investigaciones históricas, en 1949 publica su obra célebre: La lucha por la tierra en el Paraguay - con una segunda edición ampliada en 1972 -, donde recoge buena parte de su experiencia frente al Departamento de Tierras.

Los vínculos establecidos en Montevideo le abrieron las puertas el IHGU, donde participó de forma activa en distintos homenajes y realizando contactos con otras instituciones similares. Entre estas, se destaca el Instituto Paraguayo de Investigaciones Históricas (en delante, IPIH), de quien Pastore fue miembro, y fungió como articulador para distintas colaboraciones entre ambas entidades.

El presente trabajo pretende analizar el papel del mencionado paraguayo en el marco de los homenajes realizados por el IHGU en 1950. En las diversas actividades, realizadas en Uruguay y en Paraguay, distintos paraguayos - en su mayoría exiliados, compañeros militantes de Pastore - participaron de forma destacada con conferencias o discursos públicos. A partir de su correspondencia, se pretende reconstruir la red político-historiográfica de exiliados paraguayos - en particular el grupo de historiadores adscriptos al Partido Liberal -. Se analizarán las distintas conferencias y

4 Archivo del Departamento Histórico de la Gran Logia de la Masonería del Uruguay (en delante ADHGLMU), Log $\therefore$ Renacimiento $\mathrm{N}^{\circ} 78$, Diploma de Apr $\therefore$ M $\therefore$ de Carlos Pastore, 10 de noviembre de 1952.

5 Academia Paraguaya de la Historia (en delante APH), Colección Documental y Bibliográfica "Carlos Pastore", Caja N²8, Diploma de Apr.: M. de Carlos Pastore, 10 de noviembre de 1952. 
participaciones en los homenajes del IHGU en 1950, así como las comunicaciones en torno a su organización.

Se propone realizar un análisis de red ego-centrada ${ }^{6}$ partiendo del mencionado paraguayo, cruzando la información de la correspondencia con el análisis cualitativo de los discursos históricos relevados - utilizando herramientas de text mining -. Se observará cómo el pasado en torno a Artigas y Paraguay fue utilizado por estos exiliados como forma de propaganda y militancia en su oposición a los gobiernos autoritarios de su país. Teniendo en el acontecimiento que se homenajeaba en 1950, las interpretaciones sobre el "asilo político" de Artigas son aspecto interesante para entender el vínculo entre los usos del pasado y la militancia de estos exiliados.

\section{Breve estado de la cuestión}

El presente trabajo cubre tres grandes aristas: 1) El centenario artiguista y sus conmemoraciones; 2) El IHGU y sus actividades en 1950; y 3) Las redes políticohistoriográfica de paraguayos liberales en el exilio. En este sentido, es menester señalar algunos trabajos fundamentales sobre estas temáticas.

En torno a las conmemoraciones de 1950 y la participación del Instituto, el trabajo de Clarel de los Santos resulta clave. En su libro La consagración mítica de Artigas ${ }^{7}$, el autor repasa los distintos homenajes, actos y discursos que se llevaron a cabo por el centenario de la muerte del prócer uruguayo. Entre estos destaca las actividades del IHGU, y da cuenta de las conferencias los distintos paraguayos que participaron. Su trabajo permite situarse en un clima de "fervor patriótico", en un contexto de bienestar político, económico y social del Uruguay, pero no exento de contradicciones y críticas. De igual manera, en torno al Instituto en sí, los trabajos de Carlos Zubillaga resultan ineludibles. En su obra Historia e historiadores en el Uruguay del siglo XX $\mathrm{XX}^{8}$, el autor da cuenta de las distintas "comunidades historiográficas" en el país. Señala al IHGU como una institución "cercana al poder", analizando su funcionamiento y lineamientos tras su

6 Ver Imízcoz, 2003; e Imízcoz \& Arroyo Ruíz, 2011.

7 De los Santos, 2012.

8 Zubillaga, 2002. 
refundación a inicio del siglo XX. Comenta la gestión de Ariosto González, y las estrategias llevadas adelante por la institución para relacionarse con pares extranjeros. Ambos trabajos permiten conocer un panorama general de las aristas políticopatriótica e historiográficas, respectivamente. No obstante, ninguno profundiza en torno a la participación de paraguayos tanto en los homenajes artiguistas, como en el Instituto. En este sentido, la conferencia de Herib Caballero Campos permite llenar este vacío. En su disertación «La imagen de José Artigas en la historiografía paraguaya ${ }^{9}$, el autor estudia el trabajo de cinco paraguayos en este contexto: Pastore, Julio César Cháves, Efraím Cardozo, Antonio Ramos, y Juan Stefanich. Su participación se da en el marco del IHGU; a excepción del trabajo de Cardozo, todos se publicaron en la recopilación publicada en 1952. Señala las características comunes entre estos cinco trabajos, resaltando la importancia de Artigas para estos intelectuales y para el pueblo paraguayo.

En relación con la última arista de este trabajo, es menester resaltar los trabajos que han abordado la historiografía paraguaya, así como sus redes. Los distintos artículos de Liliana Brezzo resultan fundamentales, pues permiten observar los distintos momentos del desarrollo historiográfico del Paraguay; se destacan sus trabajos «El Paraguay en cinco momentos historiográficos: retos y perspectivas» ${ }^{10}$ (2009) y «La historia y los historiadores $\rangle^{11}$. En relación a los intelectuales e historiadores a trabajar, su artículo «Institucionalizar la escritura del pasado. La Academia Paraguaya de la Historia» $^{12}$ (2016) da cuenta de la fundación y evolución del IPIH. Finalmente, junto a Alfredo Boccia Romañach y Domingo Rivarola, compilan el libro Carlos Pastore Goiburú. 65 años de la Lucha por la tierra en el Paraguaya ${ }^{13}$. Allí se publican dos artículos de referencia: «Semblanza biográfica del Dr. Carlos Pastore Goiburú» (2015), autoría de su hijo, Carlos Pastore Olmedo, y «Reconstruyendo a Carlos Pastore: objetivos para una biografía intelectual» (2015) de Brezzo. Ambos permiten conocer la vida de Pastore y su inserción en el campo historiográfico del Paraguay, respectivamente.

9 Caballero Campos, 2020.

10 Brezzo, 2009.

11 Brezzo, 2010b.

12 Brezzo, 2016.

13 Boccia, Brezzo \& Rivarlo, 2015. 
Por otro lado, en relación a las redes intelectuales en torno a Pastore y los historiadores liberales paraguayos, una serie de trabajos de Tomás Sansón resultan relevantes. Sus artículos «El campo historiográfico en Paraguay en la primera mitad del siglo XX: condicionamientos y monopolio interpretativo» ${ }^{14} \mathrm{y}$ «La historiografía Liberal y la época del "Semanario". Una aproximación interpretativa»" brindan una mirada amplia en torno al funcionamiento del campo historiográfico del Paraguay. A la vez, focaliza en torno a las características comunes del grupo de historiadores adscriptos al Partido Liberal, desde sus referentes generacionales, derrotero vital y lineamientos interpretativos sobre el pasado. Finalmente, su trabajo «Carlos Pastore y "el general de la virgen espada". Memoria y destino nacional» ${ }^{16}$ resulta ineludible. Allí el autor profundiza en las interpretaciones de Pastore sobre el pasado paraguayo, y analiza su postura teórico-metodológica sobre la investigación histórica.

A partir de estas obras, se procederá a analizar el rol de Pastore en la participación de los paraguayos en los homenajes realizados por el IHGU. Se buscará problematizar las interpretaciones en torno a Artigas y el Paraguay, y observar el uso del pasado en un contexto político-historiográfico marcados por el exilio.

\section{Carlos Pastore: exilio, redes y escritura de la historia}

Carlos Agustín Pastore Goiburú nació el 16 de mayo de 1907 en Mbuyapey. Formado en el Colegio Nacional de Asunción, y egresado de la Facultad de Derecho y Ciencias Sociales, tempranamente se interesó en la política. Integrante del Partido Liberal, actuó como subsecretario de la Presidencia de José Patricio Guggiari (1928-1932). Durante la Guerra del Chaco fue Jefe de Sección de Correos y Claves del Comando Mayor, siendo reconocido por su destacada actuación. Como se mencionó, durante la presidencia de Estigarribia (1939-1940) fue designado director del Departamento de Tierras y Colonización. Tras su muerte, y el ascenso de Morínigo al poder (1940-1948),

14 Sansón, 2017.

15 Sansón, 2018.

16 Sansón, 2020. 
el Paraguay transitó una serie de gobiernos de corte autoritario, cuyo punto máximo sería la dictadura de Alfredo Stroessner.

En este contexto, Pastore emprende su exilio, viviendo en Montevideo por más de treinta años. No obstante, no fue el único que abandonó su país. Como el propio Pastore señala, en 1940 ocurre la primer gran diáspora de exiliados paraguayos en el siglo $\mathrm{XX}^{17}$. Entre estos se encontraba el grupo de intelectuales liberales, conformado por Justo Pastor Benítez (1895-1963), Justo Prieto (1897-1982) ${ }^{18}$, Efraím Cardozo (1906-1973), Antonio Ramos (1907-1984), y Julio César Chávez (1907-1989). Sansón (2018) señala que este grupo se formó en el Colegio Nacional, y en la Universidad Nacional. Fueron militantes activos del Partido Liberal, y participaron en la Guerra del Chaco en tareas de asesoramiento y apoyo logístico. Ocuparon cargos políticos, diplomáticos y administrativos, a la par que desarrollaban el periodismo ${ }^{19}$.

Todos sufrieron la experiencia del exilio debido a los acontecimientos políticos de las primeras décadas del siglo XX. Se avocaron intensamente a la investigación histórica, ocupándose de cuestiones sociopolíticas y económicas. Entendían que el estudio del pasado era una herramienta fundamental para entender los problemas del país, así como para “desmitificar" el uso ideológico de la Historia ${ }^{2021}$. La correspondencia entre

\section{Pastore, 1972.}

18 Sansón no incluye a Prieto entre este grupo. No obstante, se lo agrega pues comparte una formación, derrotero y vinculación similar a los demás. A su vez, el propio Pastore lo reconoce como historiador en el Prólogo a la obra de Andrés Flores Colombino. Ver Flores Colombino, 1972.

19 La categoría de historiadores liberales en el exilio surge de la caracterización realizada por Tomás Sansón. Responde a un conjunto de intelectuales paraguayos pertenecientes al Partido Liberal, que se dedicaron a la investigación histórica, y que sufrieron el exilio ante los avatares políticos de su país; es en este sentido que se los señala como liberales, y no como una postura ideológica strictu sensu. No obstante, el autor destaca que, debido a su formación y a trayectorias biográficas similares, conformaron un núcleo intelectual que compartían posturas teórico-metodológicas en sus interpretaciones historiográficas. Ver Sansón, 2018.

20 Sansón, 2018.

21 En este sentido, la historiografía del Paraguay presenta particularidades en relación a la región rioplatense. Brezzo y Sansón señalan en sus trabajos un desarrollo historiográfico dispar en Paraguay, en comparación con sus vecinos. Tas el fin de la Guerra de la Triple Alianza, la historiografía de cuño "mitrista" buscó demonizar los gobiernos previos, interpretando el pasado en clave de "civilización" aliados - y "barbarie" - Gaspar Rodríguez de Francia y los López -. No obstante, a finales del siglo XIX y principios del XX, interpretaciones disidentes pugnaron por una nueva interpretación del pasado. En torno al Instituto Paraguay, la "Generación del 900" sentó las bases para una interpretación que buscó revisar la historia paraguaya, en pro de "regenerar/reconstruir" el pasado por medio de la pluma de paraguayos. A inicio del siglo XX, y tras la polémica pública entre Cecilio Báez y Juan E. O’Leary, pueden identificarse una "bifurcación de caminos", donde dos tipos de historiografía nacionalista fueron ensayados: la historiografía nacionalista de vertiente erudita, y la historiografía nacionalista de corte radical (Borba Eguren, 2020). Sería esta última la que terminaría imponiéndose como historiografía 
este grupo da cuenta de un intenso intercambio de información sobre cuestiones heurísticas e interpretaciones sobre el pasado Paraguay, al mismo tiempo que coordinan acciones políticas en relación a su oposición a los gobiernos de su país.

En este sentido, las actividades intelectuales-historiográficas se entrecruzan con la militancia política. En los próximos apartados se analizará cómo esta red políticohistoriográfica se manifiesta en los homenajes artiguistas. Partiendo de la figura de Pastore como articulador de estas actividades, se establecerán características comunes al uso del pasado por parte de estos intelectuales paraguayos. Para eso se ha construido una base de datos a partir de 263 cartas relevadas del archivo de Pastore, custodiado por la APH en Asunción, y se ha tomado el período entre 1942 - inicio del exilio de Pastore - y 1952 - año en que el IHGU se publican las conferencias sobre Artigas -. Se establecieron las siguientes variables:

1) Id.

2) Remitente.

3) Institución remitente.

4) Receptor.

5) Institución receptor.

6) Nacionalidad remitente.

7) Nacionalidad receptor.

8) Fecha.

9) Año.

10) Lugar remitente.

11) Latitud remitente.

12) Longitud remitente.
13) Lugar receptor.

14) Latitud receptor.

15) Longitud receptor.

16) Texto.

17) Copia.

18) Tipo de carta.

19) Tema historiografía.

20) Tema Paraguay.

21) Tema Partido Liberal.

22) Tema Latinoamérica.

23) Tema Revolución.

24) Tema Otros.

Utilizando el software $R^{22}$, y los paquetes igraph $h^{23}$ y quanteda ${ }^{24}$, se realizará un gráfico de redes y de nubes de palabras, a fin de establecer características comunes entre la correspondencia y los discursos relevados. En relación a estos últimos, se

oficial, sobre todo con las dictaduras de Higinio Morínigo y Alfredo Stroessner, desplazando a la vertiente erudita - al exilio, como el caso de Pastore, o a una práctica disimulada para quienes permanecieron en el territorio -. Ver Brezzo, 2010; Brezzo, 2012; Sansón, 2017; y Borba Eguren, 2020b.

22 Sobre R: https://www.r-project.org/about.html.

23 Sobre igraph: https://igraph.org/r/.

24 Sobre quanteda: https://quanteda.io/ 
seleccionaron las conferencias y discursos de paraguayos compilados en la mencionada publicación del IHGU de 1952.

\section{El IHGU y los homenajes en el Centenario de la muerte de Artigas}

Antes de pasar al análisis de la correspondencia, es necesario señalar algunos aspectos del IHGU, y su incidencia en el campo historiográfico uruguayo. Originalmente, el Instituto fue fundado en 1843 por iniciativa de Andrés Lamas y Teodoro Vilardebó. Tomando el modelo del Instituto Histórico y Geográfico de Brasil ${ }^{25}$, nace como una institución privada, pero al servicio del Gobierno de la Defensa, en el contexto de la Guerra Grande (1839-1851). No obstante, el propio desarrollo del conflicto llevó a su disolución.

En 1903, un proyecto de refundación se presentó al Ministerio de Fomento. Explica Zubillaga que la iniciativa continuaba siendo privada, pidiendo financiamiento oficial a cambio de servicios en materia histórica y geográfica ${ }^{26}$. El autor señala que en 1905 la Cámara de Representantes aprobó el subsidio solicitado, pero no sería hasta 1915 cuando se conformó la segunda etapa del IHGU. Un nuevo proyecto de ley, presentado por el diputado e historiador Pablo Blanco Acevedo, propuso la creación de un Instituto Histórico y Geográfico Nacional, pero la propuesta no llegó a ser tratada por el Legislativo. Sin embargo, un grupo de intelectuales reunidos en el Ateneo de Montevideo el 29 de octubre de 1915 resolvieron la constitución del nuevo Instituto, y luego solicitaron el apoyo oficial para su funcionamiento y solvencia ${ }^{27}$.

En 1916, el Parlamento aprobó el reconocimiento del IHGU, y otorgó el subsidio votado en 1905. Se mantenía el modelo de institución privada, apoyada por el Estado en contrapartida de prestar asesoramiento sobre las temáticas en que se especializaba. Señala Zubillaga que la labor del Instituto tuvo, desde un inicio, la finalidad de

25 Ver Sansón, 2015.

26 Zubillaga, 2002: p. 88.

27 Ibid.: p. 90. 
consolidar la nacionalidad, «[...] expresada no sólo en la asociación a las celebraciones del calendario patriótico, sino en acciones de recuperación testimonial y de preservación patrimoniali ${ }^{28}$.

En las décadas siguientes el IHGU buscó ampliar su influencia, incorporando Miembros de Honor y estableciendo filiales en el interior del país. A su vez, en 1920 comienza a ser editada la Revista del Instituto Histórico y Geográfico del Uruguay. Señala Sabrina Álvarez que, en la década de 1930, la historiografía uruguaya vio emerger a nuevos historiadores "de transición" o "semi-profesionales" 29 . Provenientes ya no del viejo patriciado uruguayo - sector hegemónico en el campo historiográfico hasta inicios del siglo $\mathrm{XX}-$, sino de la nueva clase media, alcanzaron un protagonismo importante en un clima tenso local e internacionalmente.

Indica Zubillaga que, hacia 1940, las iniciativas del Instituto se:

[...] tradujeron una fluida relación con los sucesivos gobiernos, funcionando sin mayores desacuerdos el esquema subsidio/asesoramiento. El mismo respondió, por otra parte, en su viabilidad, a la inexistencia de profesionales de la disciplina, babida cuenta de la tardía configuración (que coincidiría con la clausura de la referida década) de los estudios superiores en ciencias históricas ${ }^{30}$.

Para ese momento nuevos actores le disputaron la hegemonía historiográfica al IHGU, como el Museo Histórico Nacional, y posteriormente la Facultad de Humanidades y Ciencias. Entre 1949 y 1969 la institución estuvo presidida por Ariosto González, historiador perteneciente al Partido Colorado uruguayo, muy cercano a Pastore. Señala Zubillaga que entre los colaboradores más cercanos de González se encontraban Carlos Pérez Montero, Arturo Scarone, Alberto Reyes Thevenet, Simón S. Lucuix, y Carlos A. Etchecopar ${ }^{31}$. Bajo su dirección buscó tender puentes con distintas instituciones similares en el exterior, e incorporando numerosos miembros correspondientes en el extranjero ${ }^{32}$.

28 Ibid.: p. 95.

29 Álvarez Torres, 2020.

30 Zubillaga, 2002: p. 99.

31 Ibid.: pp. 99-100.

32 Señala Zubillaga que, en la interna uruguaya, la incorporación de miembros durante este período se caracterizó por la captación de una gran cantidad de individuos que no eran expertos o conocedores de la práctica historiográfica: «La política de cooptación se desplegó en estos años con inusual intensidad, para atender antes que un reclutamiento de cultores natos de las disciplinas epónimas, el de personas vinculadas a esferas de gobierno y pertenecientes a los partidos tradicionales, que sólo de manera adventicia (en el mejor de los casos) aparecían vinculadas con algún tema o interés relacionados con la 
En este reclutamiento, Paraguay fue uno de los países con mayor cantidad de miembros correspondientes en el IHGU. Para 1952 figuran: H. Sánchez Quell, Andrés Barbero, R. Antonio Ramos, E Amarilla Fretes, Viriato Díaz Pérez, Ramón Lara Castro, Efraím Cardozo, Pablo Max Insfrán, Justo Pastor Benítez, Juan E. O’Leary, Carlos R. Centurión, Juan F. Pérez Acosta, Silvano Mosqueira, Pablo Alborno, Marciano Castelví, Modesto Guggiari, Julio César Chávez, Justo Prieto, J. Gabriel Ruiz, Emilio Saguier Aceval, Narciso R. Coimán, J. Natalicio González, Juan R. Chaves, Guillermo Tell Bertoni, Raimundo Rolón, José B. Barreré, Juan B. Otaño, Alcides Codas Papalucá, B. Casaccia Bibolini, César C. Vasconsellos, Carlos Pastore, y Enrique Riquelme García ${ }^{33}$.

Como se observa, el grupo de historiadores liberales se encuentra en este listado. No obstante, también aparecen otros intelectuales e historiadores vinculados al Partido Colorado paraguayo, siendo sus principales figuras O’Leary y Natalicio González. En este sentido, a pesar de la representación de los distintos partidos políticos paraguayos entre estos miembros correspondiente, la participación en los homenajes artiguistas de 1950 contó con una gran mayoría de adscriptos al Partido Liberal. Este aspecto va de la mano de la vinculación existente entre estos liberales y el IPIH, compartiendo miembros con el IHGU.

La relación entre los exiliados paraguayos y el Instituto uruguayo parece indicar a Pastore como uno de sus principales articuladores. Su residencia en Uruguay, así como el reconocimiento como intelectual y político destacado, le permitió conjugar la actividad histórica de estos exiliados, con las actividades del IHGU.

\section{Compartiendo el exilio: la participación de exiliados paraguayos en los homenajes a Artigas}

Como se mencionó anteriormente, para el análisis de la correspondencia se realizó una base de datos a fin de trabajar con gráficos de red y nubes de palabras. Al graficar los

disciplina. No se trataba ya de "amateurs", sino de elementos ajenos a la práctica historiográfica». Ver Ibid.: p. 101.

33 IHGU, 1952: p. VII. 
intercambios epistolares en torno a Pastore, desde 1942 hasta 1952, se observa lo siguiente:

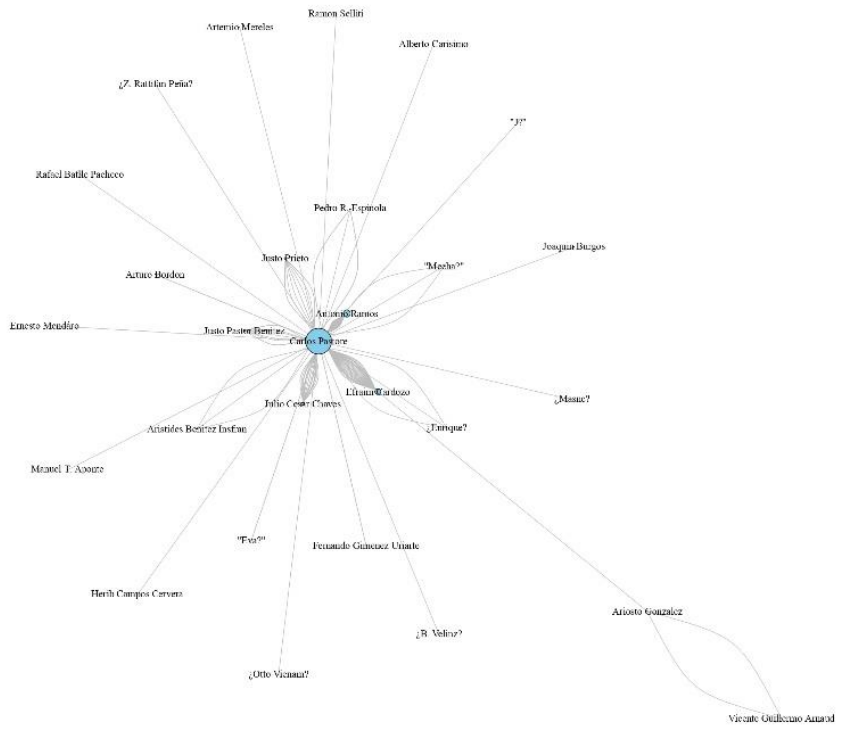

Como puede esperarse, se muestra una centralidad en torno a Pastore al tratarse de una red-egocentrada. En torno a él se observa algunos actores más: Antonio Ramos, Efraím Cardozo, Julio César Cháves, Justo Pastor Benítez y Justo Prieto. Esto da cuenta de la intensa correspondencia dentro de este grupo. Al observar la temática de las cartas de estos actores se puede ver la siguiente distribución:

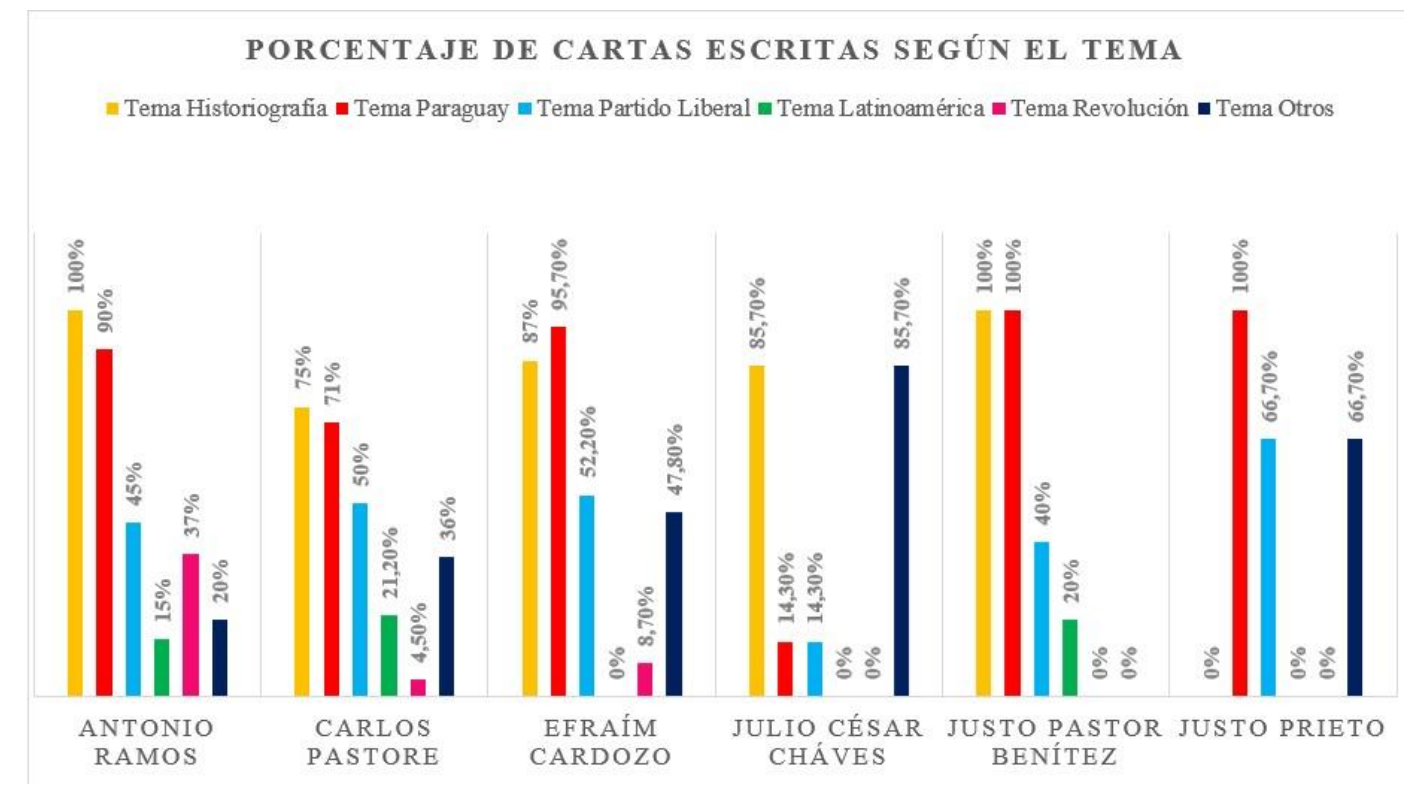


En un total de 124 cartas para el período 1942-1952, las tres temáticas predominantes en las misivas de estos cinco paraguayos - sin tener en cuenta "Otros" - son las relacionadas con Paraguay, con historiografía y con el Partido Liberal ${ }^{34}$. Esto resulta obvio al tratarse de exiliados liberales paraguayos que practican la investigación histórica - de los cinco, Prieto fue quien menos se dedicó a este último aspecto -. Este dato permite pensar la relación en torno a las actividades historiográficas y la militancia política.

Cabe preguntarse en qué consisten estas temáticas, más allá de su clasificación general. Para eso se ha construido la siguiente nube de palabras, utilizando el paquete quanteda, a partir de las cartas remitidas por este grupo de intelectuales:

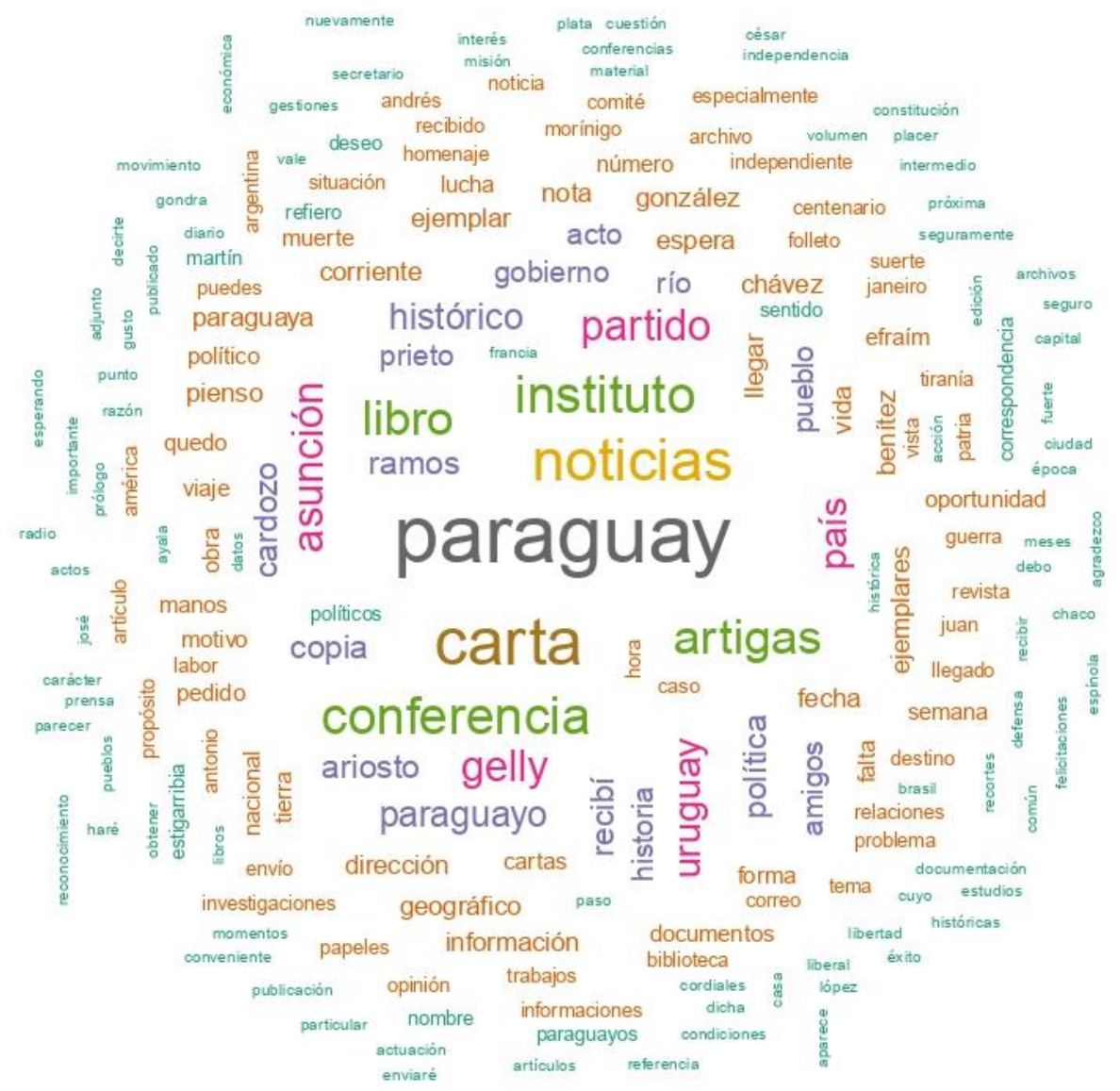

34 Es menester señalar que estas categorías no son excluyentes, pues una gran mayoría de cartas versan sobre más de un tema. 
Obviando la referencia central de "Paraguay", por las razones ya señaladas, aparecen algunas palabras que indican ciertos puntos importantes sobre el contenido de las misivas. Al graficar las veinte palabras más frecuentes se puede observar lo siguiente:

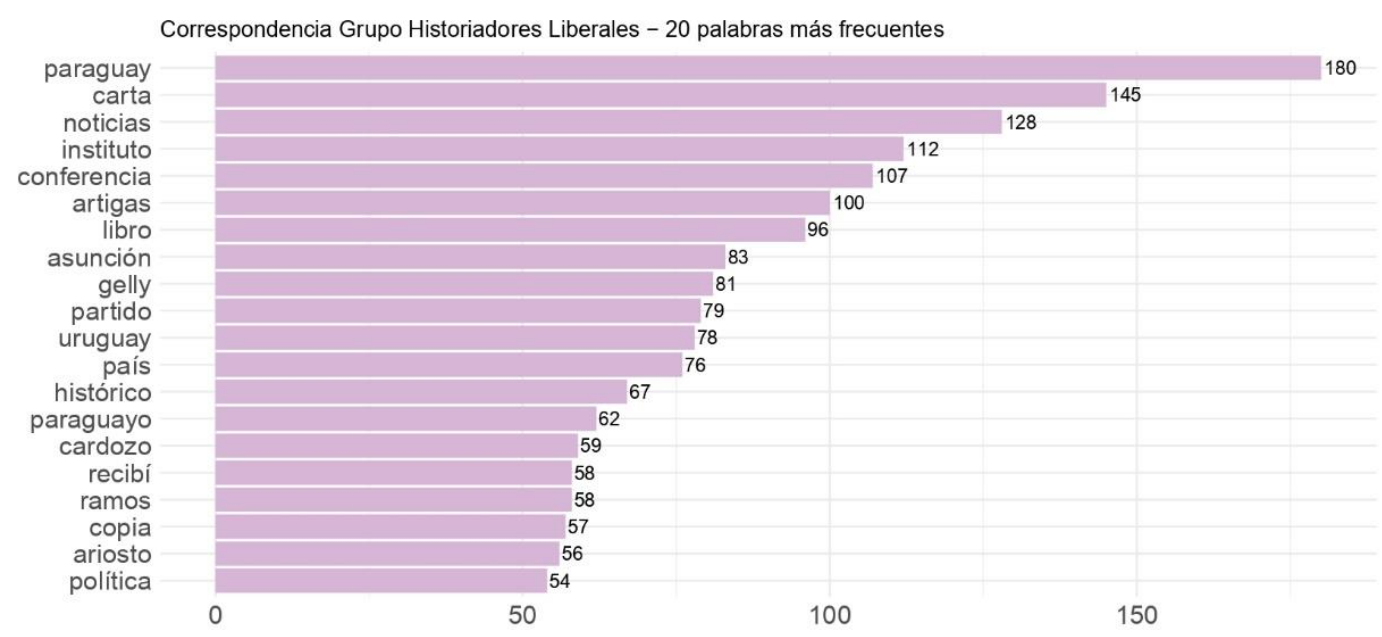

Las palabras como "instituto", "conferencia" y "Artigas" se encuentran entre las más nombradas. Este dato hace referencia a los homenajes artiguistas en cuestión. La presencia de las palabras señaladas, sumada a algunos nombres - como el del propio director del Instituto ("Ariosto") -, permiten afirmar la importancia de estas actividades en la correspondencia trabajada.

De igual manera, palabras como "libro", "copia" y "Gelly", sumado a otras que aparecen en menor frecuencia, como "historia", "archivo", "investigaciones", "documentos", "bibliotecas", etc., señalan la presencia de temáticas de corte historiográfico. En paralelo, otras palabras como "partido", "políticos", "tiranía", “Morínigo", "gobierno", entre otras., dan cuenta de esa otra dimensión política de esta red en torno a Pastore.

Teniendo en cuenta esto, es posible pensar la interacción de las esferas intelectual y política en la correspondencia relevada, particularmente en torno a los homenajes a Artigas. En los próximos parágrafos se analizará tanto el papel de Pastore en la coordinación de la participación paraguaya en los homenajes de 1950, así como las conferencias y discursos pronunciados por paraguayos. 


\section{Las gestiones de Pastore y la red político-historiográfica}

Como se señalaba, este grupo de historiadores liberales estableció una red políticohistoriográfica en la región platense. A partir la correspondencia relevada es posible graficarla, y en ella se aprecia una cercanía mayor entre Pastore y Ramos, en comparación con el resto de los intelectuales señalados. La posición de ambos en la red responde a un intenso intercambio, debido a sus funciones en sus respectivas instituciones ${ }^{35}$, así como por intereses y preocupaciones políticas en común.

En este sentido, la misiva de Pastore a Ramos del 31 de agosto de 1950 resulta un buen punto de partida. Desde Asunción, Ramos escribe a su compatriota agradeciéndole la invitación a la conferencia que dictará en el IHGU, sobre Artigas en el Paraguay. Le comenta que él escribió dos artículos en 1935 sobre el tema: «Francia y Artigas»y «El segundo Consulado». Ambos trabajos se los envió a Eduardo Salterain y Herrera, y a Ariosto Fernández; este último le habría planteado la posibilidad de publicarlos en un folleto, pero no ha tenido más noticias de él. Y comenta posteriormente:

Estoy informado que en ese país van a publicar un volumen especial, con motivo del centenario de la muerte de Artigas y en su homenaje, con los trabajos escritos al respecto del prócer oriental. Me gustaría que entre ellos se incluyan los míos mencionados. A pedido del Dr. Beniter, yo le envié copias de dichas monografias, para que él a su vez, las retransmitiese a Montevideo. De aqui es más difícil la comunicación contigo, razón por la cual no las remití a ti directamente. De consiguiente te recomiendo muy especialmente este negocio ${ }^{36}$.

35 En este sentido, cabe destacar el papel de ambos para el establecimiento de un convenio entre el IHGU y el IPIH. En 1946, el IHGU publica un folleto titulado Intercambio Cultural entre Uruguay y Paraguay. En el mismo se señala la participación de Ariosto González en el reinicio de las actividades del IPIH, el 12 de septiembre de 1946, donde se establece un "Convenio de reciprocidad entre el Instituto Histórico y Geográfico del Uruguay y el Instituto Paraguayo de Investigaciones Históricas”. González también dicta en esta instancia una conferencia titulada "El deber de la Verdad en la labor histórica". Si bien se comenta sobre este convenio entre ambas instituciones, solo se recogen las intervenciones de Ramos, Adolfo Aponte, y González en esta actividad pública. Es posible que este intercambio se haya establecido "de palabra" en 1946, y que no se haya alcanzado a firmar debido a la situación política paraguaya con la Guerra Civil de 1947. Esto se deduce a partir de la correspondencia de Pastore, quien en 1949 intercambia varias misivas con Ramos solicitando, a pedido de Ariosto González, un listado de nombres de los miembros del IPIH para el establecimiento de un convenio con su par uruguayo. No se ha podido acceder a las actas del IHGU, no obstante, en misivas posteriores a la señalada fecha se hace alusión la concreción de este tratado entre ambos institutos.

36 APH, Colección Documental y Bibliográfica "Carlos Pastore", «Carta de Antonio Ramos a Carlos Pastore», Caja No 31, 31/08/1950. 
Señala que ha tenido problemas para comunicarse con Ariosto González. Expresa que le ha escrito en reiteradas oportunidades, pero no ha obtenido respuesta, lo cual le sorprendió amargamente:

[...] dada la amistad que me une con Ariosto González, la simpatía profunda que profeso al Uruguay y mi vinculación con el Instituto Histórico, dado que yo fui el negociador y uno de los firmantes del acuerdo de correspondencia existente entre la entidad paraguaya y la orientak7.

Le pide a Pastore que averigüe qué sucede. Este responde el 9 de septiembre, comentando que su conferencia fue una respuesta a Salterain y Herrera, quien:

[...] no sabe, que, en los tiempos actuales, con las cartas de Chapultepec y la de las Naciones Unidas y de los derechos que estas consagran en defensa de los derechos humanos, numerosos exiliados politicos, en todos o casi todos los países del mundo, sufren todavía los mismos vejámenes y las mismas privaciones que sufriera Artigas en Paraguay cien años antes. Como verás, mi trabajo está un poco influenciado por la justa resistencia que produjo en mi espiritu las afirmaciones de Salterain que pueden mellar la hospitalidad de nuestro pueblo y la verdad en esta materia histórica, al presentar e interpretar los acontecimientos a que me refiero ${ }^{38}$.

Continúa expresando su descontento con la posición de su compañero del IHGU sobre el supuesto sufrimiento de Artigas en Paraguay. Señala que esta interpretación es compartida por otros autores uruguayos, e indica que este aspecto:

[...] aumenta nuestra obligación de permanecer atentos para rectificar este error histórico. Por lo demás, Artigas no necesita de la deformación de su vida en el Paraguay para mantenerse en el pedestal que con justicia ocupa y para conservar la gratitud de su pueblo y el respeto y la admiración de todos los americanos ${ }^{39}$.

Le comenta las actividades de Ariosto González y Ariosto Fernández, excusando su silencio. Señala que el Instituto planea publicar los trabajos sobre Artigas, pero que llevará tiempo; le solicita que le pida al «[...] Dr. Benitez que me envíe las copias de tus

37 Ibid.

38 APH, Colección Documental y Bibliográfica "Carlos Pastore", «Carta de Carlos Pastore a Antonio Ramos», Caja N 31, 09/09/1950.

39 Ibid. 
trabajos, que yo me encargaré, con mucho gusto, de darle los trámites del caso, o bien puedes mandarme nuevas copias para apresurar dichos trámites ${ }^{40}$. Al finalizar le informa que le escribió a su común amigo "Justo" - no se aclara apellido, por lo que no se puede asegurar que se trate de Prieto - para que se realice algún homenaje a Artigas en Asunción.

Una semana más tarde Pastore vuelve a escribir, el 16 de septiembre, comunicando que el IHGU enviaba a su secretario, Arturo Scarone, y los poetas, Carlos Sabat y Fernan Silva, en "misión cultural" para participar en los homenajes a Artigas en Asunción ${ }^{41}$. No se detalla cómo se proyectó el homenaje, ni en qué fecha se realizó, pero resulta claro de dónde nace la iniciativa.

El 2 octubre Ramos responde comentando sobre el acto realizado en el Club Unión de Asunción. Le informa que dictó una conferencia titulada «El refugio de Artigas», la cual estuvo auspiciada por el IPIH, la Junta Sanmartiniana del Paraguay y el Instituto de Numismática y Antigüedades del Paraguay. Señala que en esta actividad participaron los enviados uruguayos, y Scarone dictó una conferencia. Comenta al respecto:

Estoy completamente de acuerdo contigo respecto al poco cordial estudio de Salterain y Herrera. Los uruguayos son injustos al tratar maliciosamente de magnificar los supuestos sufrimientos de Artigas en nuestro país. Debemos rectificar, en forma definitiva, semejante falsedad histórica. Yo estoy resulto a ello. En fin, puedo afirmarte, que, de nuestra parte, hemos hecho todo lo que pudimos, para rendir digno homenaje, al célebre PROTECTOR DE LOS PUEBLOS LIBRES. Si más no bicimos es porque no estaba a nuestro alcance.

Debo decirte, confidencialmente, que la delegación intelectual uruguaya, si bien integrada por altos exponentes de la cultura oriental, no estuvo a la altura de las circunstancias, nos ha defraudado. Solamente en la Escuela Normal, Sabat Ercasty, pronunció un trabajo de categoría ${ }^{42}$

En paralelo, el IHGU continuó con su ciclo de conferencias donde participaron varios paraguayos exiliados. En estas actividades, nuevamente Pastore funge como articulador, en particular en la organización y realización de la conferencia de Cháves,

40 Ibid.

$41 \mathrm{APH}$, Colección Documental y Bibliográfica "Carlos Pastore”, «Carta de Carlos Pastore a Antonio Ramos», Caja No 31, 16/09/1950.

42 APH, Colección Documental y Bibliográfica "Carlos Pastore", «Carta de Antonio Ramos a Carlos Pastore», Caja No 31, 02/10/1950. 
el 11 de octubre de 1950 en Montevideo. El intercambio entre ambos da cuenta de esto $^{43}$.

El 8 de septiembre, Cháves le expresa a su compatriota que Ariosto González le había propuesto diserta en el ciclo de conferencias ${ }^{44}$. Su participación se iba a realizar en septiembre, pero diversos inconvenientes no permitieron concretarlo para esa fecha. Por esta razón, le pide a Pastore su conferencia en el IHGU, para saber sobré qué tema podría hablar. Este le responde el 13 del mismo mes, enviándole un recorte de prensa donde se publicita la conferencia de Chaves, quedando finalmente fijada para el 11 de octubre, según le informó González ${ }^{45}$. Le solicita a su compatriota el tema de su intervención para realizar las invitaciones correspondientes, y expresa:

Tengo entendido que eso se desprende de la publicación que adjunto, le dan a tu conferencia el mismo carácter que le dieron a aquellas que intervinieron tú, Prieto y Cardozo en el centenario del reconocimiento por el Uruguay de la independencia de nuestro país. Por todo ello, y por qué la resolución sobre la fecha de tu conferencia fue tomada antes de que recibiera tu carta, soy de parecer que debes dar tu conferencia en la fecha citada. Espero, pues, el tema de tu conferencia para que puedan preparar con tiempo las invitaciones 464.

Chaves le responde el 23 de septiembre, aceptando la fecha propuesta, y le expresa que su conferencia se concentrará en el período que va de la muerte de Francia a la muerte de Artigas ${ }^{48}$. Le propone dos títulos: «Artigas en el alma paraguaya»o «La trascendencia de Artigas en Paraguay». Agrega que desearía que Simón Lucuix sea quien lo presente, pues conoce su producción histórica. Le consulta si su referencia a Cardozo y a Prieto es porque estos estarán presentes.

43 Es menester señala que, en este intercambio, Julio César Chaves se dirige a Pastore como "Jorge Martínez". Este seudónimo se repite por casi un año, hecho que se desconoce su motivo. Tal vez se deba a cuestiones políticas, donde se apela a un seudónimo.

44 APH, Colección Documental y Bibliográfica “Carlos Pastore”, «Carta de Julio César Chávez a Carlos Pastore», Caja N 31, 08/09/1950.

45 APH, Colección Documental y Bibliográfica “Carlos Pastore”, «Carta de Carlos Pastore a Julio César Chávez», Caja N³1, 13/09/1950.

46 Ibid.

47 Otro ejemplo de participación de paraguayos en actos del IHGU, donde Pastore también fungió como articulador para su proyección y realización.

48 APH, Colección Documental y Bibliográfica “Carlos Pastore”, «Carta de Julio César Chávez a Carlos Pastore», Caja N³1, 23/09/1950. 
El 28 del mismo mes, Chaves vuelve a escribir para agregar que el IPIH lo nombró como representante ante los actos del $\mathrm{IHGU}^{49}$. Pastore responde el 2 de octubre, indicando que el título sea «Artigas en el alma paraguaya» ${ }^{50}$. Le informa que el Dr. Fernando Abente, otro emigrado paraguayo, entregará tierra de la Recolecta de Asunción, en nombre del Círculo Uruguayo Paraguayo (en delante, CUP). Con respecto a la participación de Cardozo y Prieto explica que deben resolverse algunas cuestiones financieras, y aclara:

Al referirme al carácter de tu conferencia quería significar el sentido de invitado especial que dan a tu presencia en dicho acto. Si se pudiera salvar en esa el problema financiero que implicaría el viaje de Cardozo y Prieto, te ruego me digas en la brevedad posible para que este asunto quede terminado. Demás está decir que, si otros compañeros de esa desearen venir aprovechando el feriado del 12, también se les enviarian las invitaciones correspondientes, para lo cual necesitaria con tiempo de tu aviso ${ }^{51}$.

El 11 de octubre se lleva a cabo la conferencia, con la efectiva participación de Abente y Lucuix previo a la intervención de Cháves. Tres días más tarde Pastore vuelve a escribir a su compatriota, enviando recortes de prensa sobre las buenas impresiones de su exposición.

Culminada la actividad, Pastore escribe a Ramos el 22 de octubre. Comienza acusando recibo de los materiales enviados; lo felicita por su trabajo «El Paraguay y San Martín», destacando su carácter didáctico «[...] y con sentido nacional y político, características que a mi parecer deben tener todas las expresiones intelectuales de nuestros compatriotas y de nuestros amigos políticos en estos momentos de aguda crisis nacional y política que sufre nuestro país ${ }^{52}$.

Se disculpa porque no ha podido leer su trabajo sobre Artigas, y comenta sobre la participación de distinto liberales. Destaca que fue un acto «[...] emotivo y de elevada

49 APH, Colección Documental y Bibliográfica "Carlos Pastore”, «Carta de Julio César Chávez a Carlos Pastore», Caja No 31, 28/09/1950.

50 APH, Colección Documental y Bibliográfica “Carlos Pastore”, «Carta de Carlos Pastore a Julio César Chávez», Caja N 31, 02/10/1950.

51 Ibid.

52 APH, Colección Documental y Bibliográfica "Carlos Pastore", «Carta de Carlos Pastore a Antonio Ramos», Caja No 31, 22/10/1950. 
jerarquía $\aleph^{53}$. Comenta la participación de Abente, y señala que su discurso «[...] fue muy emotivo y elocuente. Yo no sabía que fuera tan buen oradon ${ }^{54}$. En relación a Cháves señala:

[...] estuvo como siempre, bien, como acostumbra estar en estos casos. En fin, fue un acto que elevó la posición intelectual de nuestros compatriotas en Montevideo, y del cual, pienso, que podemos estar satisfechos, como paraguayos y como liberales, ya que esto fue programado por nosotros, y en él twiveron papeles destacados nuestros amigos ${ }^{55}$.

En este breve repaso del intercambio epistolar entre Cháves, Ramos y Pastore, en torno al centenario artiguista, es posible observar algunos aspectos relevantes. En primer lugar, la interacción entre las esferas historiográficas y políticas. El comentario que sobre la participación de Cháves resulta ilustrativo: "programado por nosotros, y en él tuvieron papeles destacados nuestros amigos". Lo que podría simplemente ser un acto patriótico, de contenido meramente histórico, es señalado por Pastore como una intervención política favorable a la imagen de los liberales paraguayos.

En segundo lugar, el papel de estos intelectuales en la organización de las actividades. La coordinación, invitación, y representación de las instituciones participantes no solo corrieron por canales oficiales; como se muestra en el gráfico de red, la cercanía de este grupo de paraguayos favoreció las gestiones entre el IPIH y el IHGU. Ante el silencio de las autoridades del Instituto uruguayo, Ramos recurre a Pastore para poder obtener información y realizar gestiones. Por intermedio de Cháves, le es informado a Pastore quién será designado como representante del IPIH para los actos. Y es Pastore quien interviene por el IHGU para coordinar fechas, y hasta incluso el título, en la conferencia de Cháves en Montevideo.

Estos aspectos dan cuenta de una participación que fue más allá de disertaciones públicas. Refieren, en el caso de Pastore, a un papel de articulador entre sus compatriotas y el espacio intelectual del IHGU. Como lo expresaba con respecto al acto del 11 de octubre, la importancia dada a estas actividades iba más allá de lo histórico. Era también importante “dejar una buena imagen” de este grupo de

53 Ibid.

54 Ibid.

55 Ibid. 
paraguayos liberales, y que ellos fueran los representantes del Paraguay en los actos del IHGU.

El esfuerzo llevado adelante por Pastore y compañía es un indicador de la importancia de participar, haciéndose presentes - y protagonistas - en los homenajes a Artigas. La intención señalada es rectificar el juicio sobre la vida del prócer uruguayo en el Paraguay. Las sucesivas críticas a autores e intelectuales uruguayos se dirigen a quienes "magnifican" los sufrimientos de Artigas durante su destierro. No obstante, al analizar las conferencias y discursos en sí, este aspecto parece relacionarse con otras cuestiones.

\section{Conferencias y discursos: la relación entre paraguayos y}

\section{Artigas}

Como se analizó, la participación paraguaya en los homenajes a Artigas en 1950 fue más allá de los discursos y conferencias públicas. Sin embargo, es en estos donde puede observarse cómo sus interpretaciones sobre el tema hablan de un uso del pasado, en relación al contexto político paraguayo y personal. Para este análisis se trabajará con la recopilación realizada por el IHGU, en 1952, de todas las conferencias y discursos realizados en los homenajes artiguistas en 1950 - tanto en Asunción, como en Montevideo -. De esta publicación se seleccionaron los textos de los paraguayos que intervienen: Ramos, Pastore, Cháves, Abente y Juan Stefanich ${ }^{56}$.

De igual manera que con la correspondencia, utilizando el paquete quanteda, se procedió a la construcción de una nube de palabras del conjunto de los textos:

56 Juan Stefanich, adscripto al Partido Revolucionario Febrerista, se encontraba exiliado en Buenos Aires en este período. Es invitado por el Embajado uruguayo en Argentina, Mateo Márques Castro, dictando su conferencia “Artigas, Francia y el Paraguay" el 18 de diciembre de 1950. Si bien este no pertenece al grupo de historiadores liberales, es incluido en este análisis por compartir algunas características comunes a dicho grupo. En particular, su condición de exiliado y su interés en la indagatoria del pasado paraguayo. 


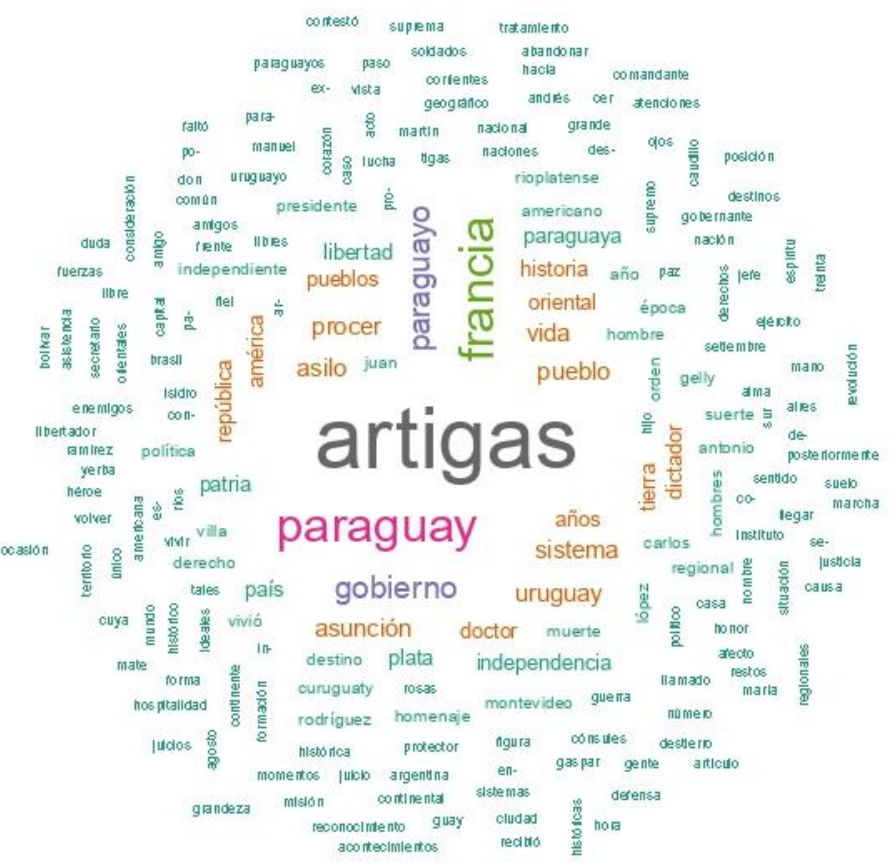

Como se aprecia, "Artigas", "Paraguay" y "Francia" aparecen como las palabras más frecuentes, por obvias razones: el período y la temática que trabajan todos refieren al ingreso y vida de Artigas en Paraguay. El top 20 de palabras refleja esta tendencia:

20 palabras más frecuentes - Conferencias de paraguayos en el IHGU (1950)

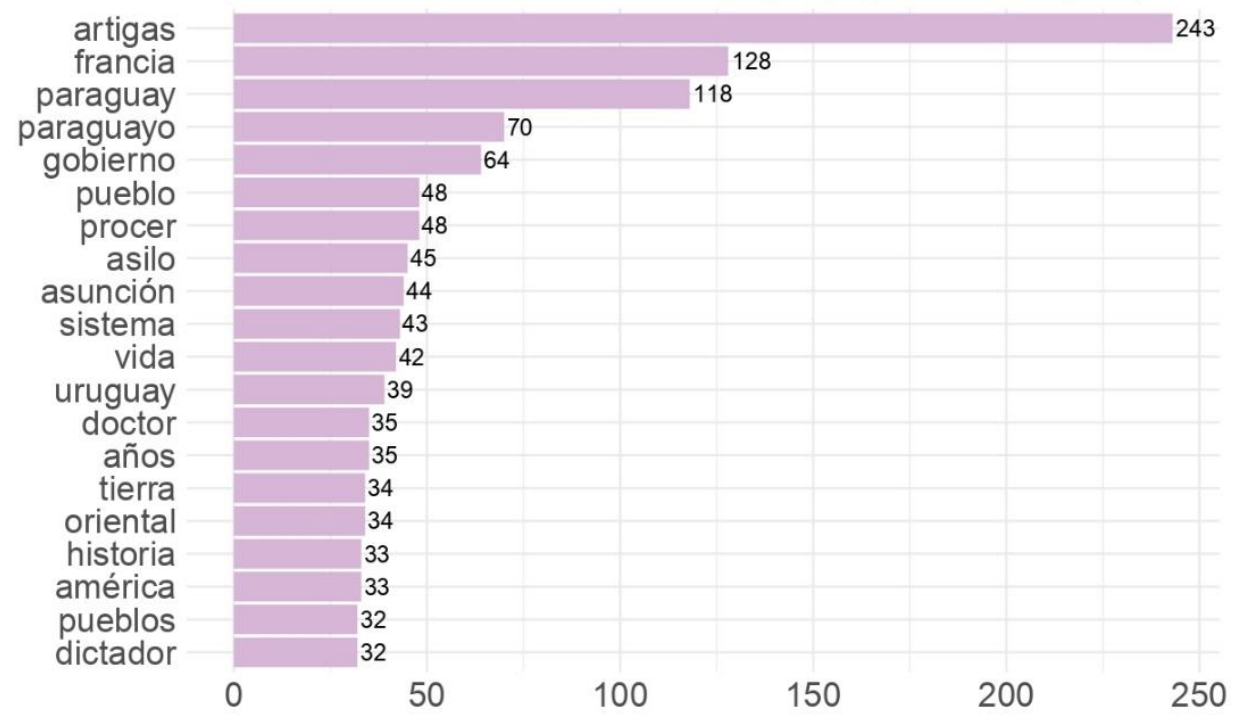


En el gráfico también aparecen palabras como "asilo", "tierra", y "América", y nombres como "Gelly" y "Rosas". Al analizar los textos, estas palabras se encuentran relacionadas a temáticas particulares que aborda cada autor. Sin embargo, a pesar de los distintos enfoques, y más allá del homenaje en cuestión, existen algunos rasgos comunes en torno a cómo miran el pasado.

En el caso de Pastore, su conferencia titulada «Artigas en el Paraguay» resalta la unión que significa la figura de Artigas para el pueblo uruguayo y paraguayo, expresando que su vida es:

[...] un capitulo común de la bistoria de nuestros dos pueblos [...] es la base de la unidad espiritual de nuestros pueblos, y de la solidaridad que, en todo tiempo, más allá de las formas protocolares, y sin otro interés que el de permanecer unidos, se guardan reciprocamente nuestras dos naciones ${ }^{57}$.

Comenta sobre el ingreso de Artigas al Paraguay, su pedido de asilo, y las atenciones recibidas por el gobierno de Francia. Analiza la publicación de El Paraguayo Independiente tras su muerte como el primer homenaje al prócer uruguayo, y señala a Juan Andrés Gelly como su autor. Expresa que Artigas, tanto como con Francia como con Carlos Antonio López, recibió atenciones que garantizaron su bienestar en Paraguay.

En la conferencia de Ramos se repiten algunos puntos señalados por Pastore. Relata el ingreso a Paraguay y la actitud de Francia. Destaca la rapidez con que el gobierno le proveyó comodidades a Artigas y sus soldados. Se detiene a analizar la negativa de Francia de entrevistarse con el prócer uruguayo, señalando que:

[...] el Dictador seguia, en el orden internacional, una politica de absoluta prescindencia en las querellas vecinales. Y si en 1820 no ayudó a Artigas contra Ramírez años después tampoco secundó al Brasil contra la Argentina, por la posesión de la Provincia Cis- platina. El Paraguay, en consecuencia, no intervino en la batalla de Ituzaingó colaborando asi en la liberación del Uruguay ${ }^{58}$.

Resalta la hospitalidad paraguaya citando distintos documentos donde Artigas expresa su agradecimiento. Se detiene a analizar la figura de asilo, y cómo Francia cumplió con

57 Pastore, 1952: pp. 21-22.

58 Ramos, 1952: p. 438. 
ese estatus otorgado a Artigas. Insiste en el buen pasar que tuvo en Paraguay, y expresa que conviene:

[...] desvanecer la especie de que Artigas haya estado en el Paraguay, algo asi, como en una cárcel o cautiverio [...] Si bien, en la época de Francia, la salida al extranjero era dificil, no era del todo imposible. Y si Artigas hubiera deseado retornar a su patria, no es exagerado afirmar, que bubiera obtenido el consentimiento del dictador ${ }^{59}$

Comenta al respecto del homenaje de El Paraguayo Independiente, y coincide con Pastore sobre la autoría de Gelly. Culmina señalando la unión de Paraguay y Uruguay a través de Artigas, diciendo:

Si Artigas vio la luz en el Uruguay, cerró sus ojos bajo el cielo del Paraguay, uniendo a estos dos paises por el influjo imponderable de su gloria. Laqo indestructible, que, al través de las vicisitudes de nuestro destino, no ban podido torcer los intereses encontrados, las pasiones desatadas, los egoísmos localistas ${ }^{60}$.

El discurso de Abente es el más breve de todos, y se da en el marco de la conferencia de Cháves en el IHGU, el 11 de octubre. Participa como representante del CUP, haciendo entrega de tierra del Cementerio de la Recolecta de Asunción al IHGU. Destaca el profundo respeto y admiración que el Paraguay tiene para con Artigas. Comenta sobre la actividad del 22 de agosto, donde fue recolectada la tierra obsequiada, señalando que el CUP hace también entrega de la documentación fotográfica de dicho momento. Habla de la unión entre Uruguay y Paraguay, y evoca el encuentro entre Artigas y Yegros como una:

[...] comunión de dos patrias en un mismo y único ideal de Libertad. Bello y sublime ideal por el que se puede y se debe luchar, por el que se puede y se debe morir, con la sonrisa en los labios, sin pena en el corazón, con gloria y con honor: ${ }^{\beta 1}$.

Posteriormente, se encuentra la conferencia de Cháves, «Artigas en el alma paraguaya». Señala que es la tercera vez que diserta en el IHGU, y que en esta oportunidad viene

59 Ibid.: pp. 442-443.

60 Ibid.: p. 448.

61 Abente, 1952: p. 275. 
en representación del IPIH. Destaca los ideales artiguistas, y la comunión con los del Paraguay. Pero explica que, en el año 1814, se produjo un "divortio-aquarum":

En 1814 se produce el momento crucial. Es cuando Artigas reclama insistentemente de los cónsules paraguayos Yegros y Francia que el Paraguay y el Uruguay unan sus fuerzas para aplastar el centralismo porteño. Pero es éste el divortio-aquarum de la historia paraguaya. El país abandona los ideales por los cuales habia luchado siempre y se impone la política del enclaustramiento del futuro dictador ${ }^{62}$.

Continúa explicando las razones su refugio en Paraguay, coincidiendo con la idea de Pastore de que buscó establecer una alianza con Francia para volver a luchar. Expresa que tras la muerte del Dictador "renace el sentimiento democrático", se llama a Congreso, y la nueva administración ofreció a Artigas retornar a Uruguay. Ante la negativa del prócer uruguayo, explica que el gobierno dispuso todas las comodidades para con él. Con la presidencia de López se realizaron gestiones para mejorar su calidad de vida, y destaca el vínculo que estableció Artigas con la familia del gobernante.

Resalta la influencia de Artigas en la transformación del país, señalando que en el período 1840-1850 el Paraguay abandonó su aislacionismo, se opuso al gobierno de Rosas, y se logra el reconocimiento de su independencia por Montevideo. Pero «[...] después de Caseros, tras la muerte de Artigas, Carlos Antonio López vuelve a la politica del aislamiento. Reaparece en la escena la sombra del viejo dictador...» ${ }^{63}$. Culmina expresando, al igual que Pastore y Ramos, que es necesario «[...] que se inicie el periodo de la rectificación, en el cual debe triunfar la verdad. Artigas no necesita de falsas coronas, ni de laureles, ni de espinas» ${ }^{64}$. Señala que su ingreso fue en carácter de asilado político, y que gozó de buena vida durante toda su residencia en Paraguay.

Finalmente, la conferencia de Stefanich, realizada en diciembre de 1950, «Artigas, Francia y el Paraguay» es la más extensa de todas. A diferencia de las demás, tiene una introducción donde explica sus lineamientos teóricos. Como señala Caballero Campos (2020), de estos cinco textos, es el único que incluye a Francia en su título. Comienza

62 Cháves, 1952: p. 288.

63 Ibid.: p. 291.

64 Ibid.: ibid. 
diciendo que, para trabajar este tema, ha procurado observar las escalas locales, regionales y continentales. Siguiendo a Hippolyte Taine, se pregunta "¿qué es el Paraguay?”, “¿Qué es Uruguay?” y “¿qué es Artigas?”; para responder explica las características comunes de la región rioplatense, y las particulares a cada nación.

$\mathrm{Al}$ respecto de Artigas señala que su intención de adentrarse al Paraguay fue la de "encontrar paz" tras sus años de lucha, sabiendo que allí tendría mayores probabilidades de ser bien acogido. Analiza su caso de asilo, e indica que a través de este "[...] nace en América una institución que con el tiempo tomaría forma y posición en el derecho internacional americano: el derecho de asilo» ${ }^{65}$ (1952, pág. 393). Describe el tratamiento de Francia para con Artigas y sus soldados, y señala que:

[...] si bien existe una gran tristeza en el destierro de Artigas, como las hay en todos los destierros, al prócer oriental no le faltó nunca ni la consideración del gobierno, ni la hospitalidad paraguaya tradicional, ni el profundo afecto con que las sencillas gentes del Paraguay acompañaron las nostalgias del gran desterrado ${ }^{66}$.

Explica la negativa del Dictador de entrevistarse con Artigas diciendo que nada tenían que conversar, pues cada uno encarnaban un "destino histórico local", por lo que lo que un encuentro «[...] habría desembocado en una conversación inocua o, lo que era menos deseable, en una discusión infructuosa ${ }^{67}$. Culmina destacando el homenaje realizado en El Paraguayo Independiente, y se opone a hablar de cautiverio para referirse a la vida de Artigas en Paraguay, pues este nunca quiso abandonar el territorio cuando tuvo la oportunidad.

Las cinco intervenciones de estos paraguayos presentan características comunes, como señala Caballero Campos ${ }^{68}:$ 1) Resaltan los vínculos entre Uruguay y Paraguay, los cuales trascienden más allá de Artigas; 2) Procuran rectificar las interpretaciones sobre la vida de Artigas en Paraguay, señalando que allí gozó de buen trato, y que decidió permanecer en el territorio cuando se le ofreció su salida; y 3) Analizan la figura de asilo político, siendo el caso de Artigas pionero para el derecho internacional americano.

65 Stefanich, 1952: p. 393.

66 Ibid.: p. 399.

67 Ibid.: p. 402

68 Ver Caballero Campos, 2020. 
No obstante, estos rasgos comunes van más allá de una interpretación histórica. Si se recuerdan las palabras de Pastore, destacando el buen desempeño de los paraguayos y, particularmente, liberales - en estos actos, es posible pensar estas intervenciones públicas desde otro punto de vista.

Al momento de referirse al ingreso de Artigas al Paraguay, todos destacan las atenciones recibidas, pero la negativa de Francia a entrevistarse con él. En su mayoría, se detienen a analizar su gobierno, señalando las limitaciones de libertades civiles y su carácter dictatorial. En este sentido, Pastore expresa que la vida de Artigas durante el gobierno de Francia siguió la misma suerte que el pueblo paraguayo: prohibición de abandonar el territorio, limitación de sus derechos cívicos «[...] y su existencia fue regida por la inflexible voluntad del dictadon ${ }^{69}$. Y agrega:

Como gobernante, como conductor de ejércitos populares y como desterrado o prisionero politico, la voluntad y el destino de Artigas fue siempre identificarse con los pueblos. Artigas no podía ser libre en medio de un pueblo oprimido. Por eso el prócer se identificó en su destierro con el pueblo paraguayo, sufrió el dolor de la pérdida de sus libertades civicas, y solo mejoró su suerte cuando el régimen de gobierno de José Gaspar Rodriguez. de Francia, fue sustituido por el de Carlos Antonio Lópezz

En similar sintonía, Cháves señala el carácter dictatorial del gobierno de Francia al hacer referencia a lo acontecido tras 1814, en la ya citada mención al encuentro de Yegros y Artigas. Destaca los cambios producidos tras la muerte del Dictador, haciendo referencia al "renacer del sentimiento democrático" en el Paraguay:

Asunción, la capital ilustre, la ciudad fundadora de ciudades, va reanimando lentamente su vida. El pueblo paraguayo, aletargado, pero no vencido, despierta. Renace el sentimiento democrático. Se pide el fin de la dictadura y la organización de un gobierno democrático: ¡CONGRESO! es la voz de orden de la ciudadanía ${ }^{71}$.

Estas descripciones insisten en la falta de libertades y derechos, aspecto que parece relacionarse con la situación de los autores. Como militantes contra gobiernos autoritarios, las críticas a gobiernos similares en el pasado se hacen extensiva al

69 Pastore, 1952: p. 25.

70 Ibid.: ibid.

71 Cháves, 1952: p. 289. 
presente. En sintonía con lo que señala Sansón ${ }^{72}$, este grupo de intelectuales e historiadores entendían que era necesario "desmitificar" el pasado. Las críticas al gobierno de Francia - y que Cháves extiende a López, tras la caída de Rosas - se enmarcan en esta actitud. En otras palabras, a través de la experiencia de Artigas, se describe el gobierno que le dio asilo; un gobierno que, si bien dispensó todas las atenciones al prócer, se caracterizó por su falta de libertades civiles.

En contrapartida, se destaca la actitud del pueblo paraguayo, con el que se identifica a Artigas. Expresa Abente, al comenzar su discurso, que en Paraguay recibió:

[...] calory abrigo, es decir lo que necesitaba el náufrago, el hombre de las grandes tormentas. El calor, no se lo podía dar José Gaspar Rodríguez de Francia, pero lo recibio del pueblo paraguayo con cuya suerte, y fiel a sus ideales. Artigas se identificó de inmediato. Y el pueblo paraguayo le correspondió con la misma lealtad, aprisionándolo para siempre con su cariño ${ }^{73}$.

Todos los autores resaltan la hospitalidad paraguaya que rodeó al prócer, y en ese sentido se basan en la crítica a las afirmaciones sobre el "cautiverio de Artigas". Señalan su decisión de permanecer en el territorio a pesar de las oportunidades que tuvo para abandonarlo. Esa identificación entre Artigas y el pueblo paraguayo puede observarse en las palabras de Pastore cuando comenta sobre las investigaciones en torno al tema:

Los trabajos publicados hasta abora autorizan a afirmar, que Artigas se dirigió al Paraguay en 1820 impulsado por los mismos sentimientos y propósitos que le guiaron años antes para informar al gobierno de Asunción la situación del Uruguay durante el éxodo del pueblo oriental; que durante la tiranía de José Gaspar Rodríguez de Francia, Artigas se identificó con el pueblo paraguayo; y que después de desaparecido el régimen de aquel gobernante, Artigas gozó de libertad para decidir sus actos, falleciendo de muerte natural, rodeado del afecto del pueblo y del respeto y las atenciones de sus gobernantes ${ }^{74}$.

Este punto toma otro cariz al observar cómo se caracteriza al prócer uruguayo. Pues, si se tiene en cuenta que los autores de conferencia se encontraban exiliados, o con sus libertades recortadas, no resulta extraño que se resalte el carácter de "Protector de los

72 Ver Sansón, 2018; y Sansón, 2020.

73 Abente, 1952: p. 273.

74 Pastore, 1952: p. 33. 
Pueblos Libres". Cuando Ramos comenta sobre las "Instrucciones del Año XIII" expresa:

Tales fueron las tendencias de las célebres instrucciones del año XIII. Respetó la voluntad popular, dada su vocación republicana "Mi autoridad emana de vosotros y ella cesa por vuestra presencia soberana", expresó frente a los diputados en la Asamblea del Peñarol. Sabia enseñanza para las democracias americanas, que con frecuencia olvidan las fuentes originarias de la autoridad, para dejar paso a las corrientes, siempre funestas, de la fuerza. En las luchas por la redención de los pueblos oprimidos, su emblema lucia esta divisa eterna y luminosa: "Con libertad no ofendo ni temo" ${ }^{\text {,75 }}$

Señala que estas palabras no fueron en vano, pues Uruguay «[...] recogió las inquietudes, las tendencias y las glorias del adalid esclarecido» ${ }^{76}$. Stefanich también va por el mismo camino, y al concluir su conferencia destaca la vigencia de los ideales artiguistas, expresando:

Artigas no es un hombre del pasado, encerrado en los recintos de la bistoria y de los archivos. Es un hombre del presente y está con nosotros en este momento. Vive nuestra ansiedad y nuestras preocupaciones, comparte nuestras inquietudes y alienta nuestras esperanzas. En medio de este mundo en zozobra, castigado por la guerra, desequilibrado por la inseguridad y el temor, en presencia de un nuevo peligro que se cierne sobre la bumanidad como una tormenta, nos dicta su palabra y su mensaje para salvar el legado político e bistórico de América y del mundo: "Con libertad, ni ofendo ni temo". El viejo lema de Artigas es lema de América: Contra todos los absolutismos, jen la paz como en la guerra!'"r7.

De la misma manera, Cháves señala el justo homenaje que se realiza, pues Artigas «Sostuvo la autodeterminación de los pueblos, combatió por los derechos de las provincias ahogadas por un sistema secular de trabas y oprobios ${ }^{78}$. Y concluye:

"Con libertad ni ofendo ni temo". Con esa divisa, que fue suya, las nuevas generaciones marchan hacia el sueño de este Quijote idealista e impenitente que, como el de Dario lo vemos "coronado de un áureo yelmo de ilusión - que nadie ha podido vencer todavía por la adarga en brazo toda fantasía y la lanza en ristre, todo corazón". En marcha hacía una América que sea en grande lo que es el Uruguay en pequeño, isla privilegiada en un mundo atormentado y en zozobra.

75 Ramos, 1952: p. 448.

76 Ibid.: ibid.

77 Stefanich, 1952: p. 408.

78 Cháves, 1952: p. 293. 
Asilo de todas las libertades, garantía de todos los derechos, amparo de todas las creencias, bastión de la democracia, jtumba del despotismo! Y cuando ese sueño, su sueño, se haya impuesto y triunfado, incluso en esa tierra paraguaya que le amortajó con su carne morena, en ese Paraguay que tanto amó y que tanto le amó, entonces, resonará de nuevo, en el atardecer de su agonía, al entrar la noche, de cielo estrellado y perfumada de azabares y jazmines, su grito postrero: "Traeme mi caballo". Y Montado nuevamente en su corcel, otra vez estará en marcha, no bacia Carumbé y Tacuarembó, sino hacia Las Piedras y Guayabo, para ganar su última, su grande, su definitiva victoria ${ }^{79}$.

La identificación del pueblo paraguayo con los ideales artiguistas parece tender un puente hasta su presente. Los tres autores citados refieren a su carácter de luchador de la libertad, "contra todos los absolutismos". La mirada sobre Paraguay y Artigas se relaciona con el presente de los autores; su militancia contra nuevos gobiernos autoritarios es también resaltar los ideales pasado, que siguen vigentes en la lucha actual. Las críticas al pasado se vuelven alusiones a la falta de libertades en el presente, de igual manera que la solidaridad y el asilo político en el presente, se vincula con el de Artigas.

Las palabras de Cháves van en este camino cuando pone el caso de Uruguay - uno de los países que mayor cantidad de paraguayos recibió hacia mediados del siglo XX en la región - como "bastión de la democracia y tumba del despotismo". Ramos también señala esto, cuando explica que la vinculación de Artigas con Paraguay no es solamente por su "refugio", sino porque este proviene de:

[...] esa generosa tierra de la hidalguía, el Uruguay, donde la amistad se brinda sin dobleces, la cultura se prodiga luminosa, el bienestar llega a todas las capas sociales sin distinción y las virtudes civicas se enaltecen en el ejercicio pleno de la libertad ${ }^{80}$.

Más allá de tratarse del prócer nacional, se reconoce en Uruguay las mismas virtudes atribuidas a Artigas: libertades civiles y democracia. Estos conceptos sobre la política oriental son destacados en distintas misivas en la correspondencia relevada ${ }^{81}$. Abente

79 Ibid.: p. 294.

80 Ramos, 1952: p. 433.

81 El 17 de marzo de 1948, Ramos le escribe a Pastore informándole sobre actividades del Partido Liberal en asuntos internacionales. Acusa recibo de informaciones que su compatriota le remite sobre su militancia en Uruguay, y expresa que esos datos le serán de utilidad «[...] para tu acción en esa noble tierra de la libertad. Tu acción, hoy más que nunca no debe decaer y debe continuar eficaz como 
ejemplifica esta idea cuando señala el caso de exilio de Estigarribia en Montevideo en 1936. Al indicar que la hija de dicho Mariscal, Graciela Estigarriba, fue quien preparó la caja de madera que contiene la tierra que entrega por el CUP, expresa:

Ese puñado de tierra de que he sido portador, fue acondicionado en esta caja que, manos de mujer paraguaya la preparara con una gran ternura. Cualquier mujer paraguaya, Señor Presidente, hubiera puesto la misma dulzura en su preparación; pero una feliz circunstancia ba querido que fuera la bija de un gran soldado paraguayo, la que cumpliera esa misión: Graciela Estigarribia, quien acompañó a su padre, cuando un día aciago, descendió por el anchuroso río epónimo, que defendiera con gallardía sin igual porque el destino quiso que el dolor del destierro, completara la faceta que le faltaba a su recia personalidad y llegara de ese modo hasta la serenidad de estas playas Orientales para curar en ellas, con el cariño de los uruguayos, las heridas del exilio, que eran también heridas de la Patria. ${ }^{2}$.

El pasado común entre Artigas, Paraguay y Uruguay, es homenajeado e interpretado por estos intelectuales en un contexto de exilio y gobiernos autoritarios. Las críticas al pasado autoritario de Francia y de López, se encaminan a desmitificar discursos nacionalistas que reivindican gobiernos autoritarios. En la identificación de Artigas con el pueblo paraguayo, se enaltecen los ideales de libertad, democracia y republicanismo en un marco de militancia política. Y en referencia al asilo político, se destaca la actitud paraguaya del pasado, al igual que la actitud que tiene en el presente el Uruguay.

Las conferencias y discursos de estos paraguayos pueden ser interpretado bajo estos puntos, permitiendo observar lo que la red y la correspondencia indicaban: una conjunción entre las esferas historiográficas y de militancia. El estudio, reflexión y homenaje en torno a Artigas y el Paraguay, es también un acto de militancia por un discurso histórico que busca desmitificar los relatos nacionalistas, a la vez que exaltan los valores e ideas que estos intelectuales defienden, frente a los gobiernos autoritarios del Paraguay.

anteriormente, porque como tú dices, o bien lo dices, no con lamentos derribaremos la dictadura si no con la acción sostenida, disciplinada y coordinada». Ver APH, Colección Documental y Bibliográfica "Carlos Pastore”, «Carta de Antonio Ramos a Carlos Pastore», Caja N 31, 17/03/1948.

82 Abente, 1952: p. 277. 


\section{Consideraciones finales}

A lo largo de este trabajo se ha procurado observar la participación de Carlos Pastore y otros paraguayos en los homenajes al Centenario de Artigas, organizados por el IHGU. Gracias a la correspondencia, es posible reconstruir las redes políticohistoriográfica en torno a dicho intelectual, pudiendo observar características comunes al grupo de historiadores liberales paraguayos.

De igual manera, el estudio de la correspondencia permite observa el papel de Pastore en la organización y coordinación de la participación de paraguayos en las actividades, tanto del IPIH como del IHGU. Las misivas analizadas de Ramos, Pastore y Cháves dan cuenta de la importancia otorgada a participar en los homenajes, así como el sentido de representar a su país con individuos del Partido Liberal.

Por otro lado, a través del análisis cualitativo de las conferencias dictadas por paraguayos en estos homenajes, es posible corroborar la tendencia de conjunción entre las esferas historiográficas y política, que resulta del análisis cuantitativo de la correspondencia. En este sentido, se identificaron características comunes a los cinco autores que participan en las actividades de 1950, y analizo cómo las interpretaciones sobre el pasado se relacionan con el contexto de los autores.

En primer lugar, se observó una descripción sobre la vida de Artigas en Paraguay, resaltando su buen pasar durante su exilio. No obstante, en esta descripción, se señalan las faltas de libertades impuestas por los gobiernos de Francia y López. Se procura desmentir el relato del "cautiverio de Artigas", señalando las buenas atenciones del gobierno paraguayo, a la vez que se denuncia el carácter autoritario del mismo. Esta "rectificación" del pasado es también una acción de desmitificación de los primeros gobiernos del Paraguay independiente.

En segundo lugar, surge del análisis una intención por identificar al pueblo paraguayo con Artigas y sus ideales. Se destaca su carácter de "Protector de los Pueblos Libres", su republicanismo y sus valores democráticos. Incluso, se señala cierta influencia de Artigas sobre el gobierno de López, donde el Paraguay gozó de mayores libertades, y que tras su muerte retorna a una actitud despótica. Se señalan la vigencia de estos ideales, haciendo referencia a la necesidad de hacerlos efectivos en el presente de los 
autores; nuevamente, se mira en la figura de Artigas los ideales detrás de la militancia que llevan adelante los intelectuales que intervienen.

Finalmente, se analiza la figura del asilo político, destacando la actitud y hospitalidad del Paraguay. Actitud similar a la que la mayoría de los autores le destacan al Uruguay, enlazando nuevamente los ideales artiguistas con la Nación que lo homenajea a cien años de su muerte.

En este sentido, se puede apreciar como los homenajes son utilizados para hablar del presente de los paraguayos estudiados. La participación de estos intelectuales estudiados da cuenta de cómo el pasado es mirado a través del contexto político que los interpela. La importancia otorgada a estos homenajes, como forma de dar a conocer sus interpretaciones del pasado artiguista, es también una actitud de militancia por rectificar la vida de Artigas en Paraguay, y por resaltar los ideales comunes a los defendidos por estos paraguayos. 


\section{FUENTES}

Ineditas

\author{
ADH-GLMU, $\log \therefore$ Renacimiento $\mathrm{N}^{\circ}$ \\ 78 y Log $\therefore$ Río de la Plata $N^{\circ} 121$. \\ APH, Colección Documental y \\ Bibliográfica "Carlos Pastore", Caja No \\ 9, $\mathrm{N}^{\circ} 10, \mathrm{~N}^{\circ} 13, \mathrm{~N}^{\circ} 28, \mathrm{~N}^{\circ} 29, \mathrm{~N}^{\circ} 30$, \\ $\mathrm{N}^{\circ} 31, \mathrm{~N}^{\circ} 32, \mathrm{~N}^{\circ} 33$.
}

Éditas

Abente Haedo, F. 1952, "Homenaje paraguayo a Artigas. Discurso del Dr. Fernando Abente Haedo" en IHGU, Artigas. Homenaje en el centenario de su muerte, Imprenta Nacional, Montevideo, pp. 273 a 278.

Cháves, J. C. 1952, “Artigas en el alma paraguaya" en IHGU, Artigas. Homenaje en el centenario de su muerte, Imprenta Nacional, Montevideo, pp. 287 a 294.

González, A. 1946, Intercambio Cultural entre Uruguay y Paraguay, Imprenta "El Siglo Ilustrado", Montevideo.

IHGU, 1952, Artigas. Homenaje en el centenario de su muerte, Imprenta Nacional Montevideo.

Pastore, C. 1952, "Artigas en el Paraguay" en IHGU, Artigas. Homenaje en el centenario de su muerte, Imprenta Nacional, Montevideo, pp. 21 a 33.

Ramos, R. A. 1952, "El refugio de Artigas en el Paraguay" en IHGU, Artigas. Homenaje en el centenario de su muerte, Imprenta Nacional, Montevideo, pp. 433 a 449.

Stefanich, J. 1952, "Artigas, Francia y el Paraguay" en IHGU, Artigas. Homenaje en el centenario de su muerte, Imprenta Nacional, Montevideo, pp. 381 a 408.

\section{BIBLIOGRAFÍA}

Álvarez Torres, S. 2020, "Entre la tradición y la profesionalización. La historiografía uruguaya en la primera mitad del siglo XX" en Sansón
Corbo, T. (coord.), El laberinto de Clio: La definición de los campos historiográficos en la región platense (primera mitad del siglo XX), Tiempo de Historia, Asunción, pp. 147 a 180.

Boccia Romañach, A. Brezzo, L. \& Rivarola, D. 2015, Carlos Pastore Goiburú. 65 años de la Lucha por la tierra en el Paraguaya, Ediciones y Ares S.A. Asunción.

Borba Eguren, M. 2020, "Relatos de victoria, historia de vencidos. La historiografía paraguaya entre 1895 y 1954" en Sansón Corbo, T. El laberinto de Clío. La definición de los campos historiográficos en la región platense (primera mitad del siglo XX), Tiempo de Historia, Asunción, pp. 211 a 247.

Borba Eguren, M. 2020b, "Visiones del Paraguay. Las "Representaciones del Pasado" en la Revista del Instituto Paraguayo" en Estudios Paraguayos, Vol. XXXVIII, Núm. 2, pp. 191 a 224.

Brezzo, L. 2009, "El Paraguay en cinco momentos historiográficos: retos $y$ perspectivas" en Casal, J. M. \& Whigham, T. Paraguay: nacionalismo y guerra, Servilibro, Asunción, pp. 61 a 78.

Brezzo, L. 2010a, “'Reparar la Nación'. Discursos históricos y responsabilidades nacionalistas en Paraguay" en Historia Mexicana, El Colegio de México, México, pp. 197 a 242.

Brezzo, L. 2010b, "La historia y los historiadores" en Telesca, I. Historia del Paraguay, Taurus, Asunción, pp. 13 a 32.

Brezzo, L. 2012, "En el mundo de Ariadna y Penélope: Hilos, tejidos y urdimbre del nacimiento de la Historia en el Paraguay" en Scavone Yegros, R. \& Scavone Yegros, S. Polémica sobre la Historia del Paraguay, Tiempo de Historia, Asunción, pp. 13 a 65.

Brezzo, L. 2015, "Reconstruyendo a Carlos Pastore: objetivos para una biografía intelectual" en Boccia Romañach, A. Brezzo, L. \& Rivarola, D. Carlos Pastore Goiburú. 65 años de La lucha por la tierra en el Paraguay, Ediciones y Artes S.A. Asunción.

Brezzo, L. 2016, "Institucionalizar la escritura del pasado. La Academia Paraguaya de la Historia (1937-1965)" en Anuario de Estudios Americanos, Vol. LXXIII, Núm. 1, pp. 291 a 317.

Caballero Campos, H. 2020, "La imagen de José Artigas en la historiografía paraguaya" en Webinar Bicentenario de la llegada del Gral. José Gervasio Artigas al Paraguay y primer asilo político en las Américas. Disponible en 
https://www.youtube.com/watch?v=bo0SrU Eh6q8\&t $=5214$ s [Consulta: 15 de diciembre de 2020].

de los Santos, C. 2012, La consagración mítica de Artigas. 1950. Homenajes y discursos a cien años de su muerte. Cultos, memorias e identidad, Ediciones Cruz del Sur, Montevideo.

Imízcoz, J. M. 2003, “Actores, redes, procesos: reflexiones para una historia más global” en Revista da Faculdade de Letras, V, pp. 115 a 140.

Imízcoz, J. M. \& Arroyo Ruíz, L. 2011, "Redes sociales y correspondencia epistolar. Del análisis de las relaciones personales a la reconstrucción de redes egocentradas" en Redes. Revista Hispana para el Análisis de Redes Sociales, Vol. XXI, pp. 98 a 138.

Pastore Olmedo, C. 2015, "Semblanza biográfica del Dr. Carlos Pastore Goiburú" en Boccia Romañach, A. Brezzo, L. \& Rivarola, D. Carlos Pastore Goiburú. 65 años de La lucha por la tierra en el Paraguay, Ediciones y Artes S.A., Asunción.

Pastore, C. 1972, "Prólogo" en Flores Colombino, A. La fuga de intelectuales. Emigración paraguaya, Talleres Gráficos de la Comunidad del Sur, Montevideo, pp. 17 a 31.

Sansón Corbo, T. 2015, Despertar en Petrópolis. Andrés Lamas y la influencia de Brasil en la Historia de los Estados de la Cuenca del Plata en el siglo XIX, Sicut Serpentes, Montevideo.

Sansón Corbo, T. 2017, "El campo historiográfico en Paraguay en la primera mitad del siglo XX: condicionamientos y monopolio interpretativo" en Historiografía, Núm. 13, pp. 53 a 73.

Sansón Corbo, T. 2018, "La historiografía Liberal y la época del "Semanario". Una aproximación interpretativa" en Campos Caballero, H. \& Gómez Florentin, C. Nación y Modernidad en Moldes de Plomo. La época de 'El Semanario de Avisos y Conocimiento Útiles' (18531868), CONACYT-PROCIENCIA-UNA, Asunción, pp. 41 a 54.

Sansón Corbo, T. 2020, “Carlos Pastore y 'el general de la virgen espada'. Memoria y destino nacional en Paraguay" en Revista de Historia de América, Núm. 159, pp. 161 a 178.

Zubillaga, C. 2002, Historia e historiadores en el Uruguay del Siglo XX, Librería de la FHCE, Montevideo. 